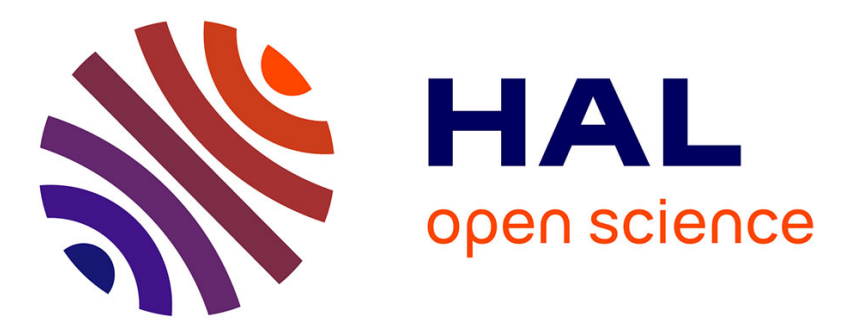

\title{
The Development of a Method of Measuring a Condensed Matter Electroconductivity for Investigation of Dielectric-Metal Transitions in a Shock Wave
}

S. Gilev, T. Mihailova

\section{- To cite this version:}

S. Gilev, T. Mihailova. The Development of a Method of Measuring a Condensed Matter Electroconductivity for Investigation of Dielectric-Metal Transitions in a Shock Wave. Journal de Physique IV Proceedings, 1997, 07 (C3), pp.C3-211-C3-216. 10.1051/jp4:1997338 . jpa-00255495

\author{
HAL Id: jpa-00255495 \\ https://hal.science/jpa-00255495
}

Submitted on 1 Jan 1997

HAL is a multi-disciplinary open access archive for the deposit and dissemination of scientific research documents, whether they are published or not. The documents may come from teaching and research institutions in France or abroad, or from public or private research centers.
L'archive ouverte pluridisciplinaire HAL, est destinée au dépôt et à la diffusion de documents scientifiques de niveau recherche, publiés ou non, émanant des établissements d'enseignement et de recherche français ou étrangers, des laboratoires publics ou privés. 


\title{
The Development of a Method of Measuring a Condensed Matter Electroconductivity for Investigation of Dielectric-Metal Transitions in a Shock Wave
}

\author{
S.D. Gilev and T.Y. Mihailova* \\ Lavrentyev Institute of Hydrodynamics, Lavrentyev prosp. 15, Novosibirsk 630090, Russia \\ * Novosibirsk State University, Pirogova ul. 2, Novosibirsk 630090, Russia
}

\begin{abstract}
The electromagnetic method of investigating the dielcctric-metal transition under shock compression of condensed matter is discussed. The investigation of transient electromagnetic processes is performed for the measuring cell comprising two conductive regions (the reference conductor, the test matter). The model $E(t)$ dependencies of the electric field are found. They can be compared with the corrcsponding expcrimcntal dependencies of the voltage $V(t)$. The $E(t)$ curves are proved to be essentially dependent on thic conductivity value and the nature of the conductivity change behind a shock front. The analysis performed provides the basis for the interpretation of the voltage records taken from the experiments with the highly porous aliminium.
\end{abstract}

Résumé : On discute la méthode d'investigation de la transition diélectrique-métal sous une compression par choc de la matière condensée. Les processus électromagnétiques transitoires sont mesurés par une cellule comprenant deux domaines conductifs (conducteur étalonné. matière testée). On a modélisé la dépendance du champ électrịue en fonction ju temps $E(t)$, qui peut ètre comparée avec la dépendance expérimentale de la tension en fonction du temps V(t). Il apparaìt que les

courbes $E(t)$ dépendent considérablement de la valeur de la conductibilité de la matière et du caractère du changement de conductibilité derrière le front du choc. L'analyse effectuée forme une base à l'interprétation des enregistrements de lá tension dans les expériences avec la poudre d'aluminium hautement poreuse.

\section{THE INTRODUCTION}

Methods of measuring the electroconductivity of condensed matter in a shock wave are presently developed for the electromagnetic equilibrium in a test material [1-4]. In this case the electrical engineering approach can be used. It allows one to relate simply the voltage registered with the specimen resistance and then using the scale coefficients to obtain the matter electroconductivity. The electromagnetic equilibrium condition is not necessarily fulfilled in a shock wave

The relaxation time of the electromagnetic field in the matter is $t_{*} \approx \mu \mu_{0} \sigma x^{2}$ ( $\mu$ is the magnetic permeability, $\sigma$ is the electroconductivity, $x$ is the matter thickness). For the copper conductor $1 \mathrm{~mm}$ thick, the time $t_{*}$ is about $70 \mu \mathrm{s}$. This highly exceeds the life time of the pressure zone in a shock wave. Therefore the electromagnetic state of the metallic shocked specimen having a sufficient thickness is nonequilibrium.

Lack of a satisfactory experimental solution of the problem of registering the dielectric-metal transitions in a shock wave has been pointed permanently during the few decades [ $1-4]$. It was clear since the $19(60)$ s that the main difficulty in measurements is the transient electromagnetic processes in the measuring cell consisting of the electric shunt and the test material

The problem of measuring the electroconductivity in nonequilibrium electromagnetic conditions has been raised in [5]. The experimental method suggested is based on the analysis of the transient electromagnetic response of the measuring cell to a shock action. The present paper is devoted to further developments of the new experimental method. It describes the justification and advancement of the electromagnetic method of registering the dielectric-metal transitions in a shock wave. 


\section{THE MEASURING SCHEME}

To investigate the dielectric metallization in a shock wave the scheme shown on Fig. 1 is used. Here, the following numerical notations are used: 1 is the metallic foil (the electric shunt), 2 is the test matter (ilie specimen), 3 is the leads, 4 is the measuring unit (the oscilloscope), 5 are the dielectrics. A plane shock wave propagates through the cell from the top down. The leads are placed in the same plane with the foil and are connected to the measuring coaxial cable outside of the shock wave region. The current in the measuring cell is generated by the outer source and is constant in the course of measurements. On entering a shock wave into the test matter the conductive region arises there. The process of the current redistribution in the measuring cell is the current diffusion from the shunt to the matter metallized. To study the possibilities for determining the conductivity there is a need to understand how the voltage registered as $V(t)$ is due to the electromagnetic field pattern in the measuring cell.

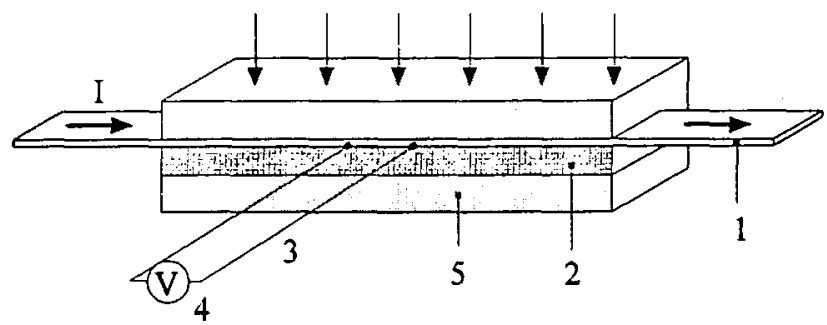

Figure 1: The measuring scheme for investigation of the dielectric-metal transition in a shock wave.

The voltage at the measuring unit (the voltmeter) is

$$
V=-\frac{\partial \Phi}{\partial t}-\oint \frac{\vec{j}}{\sigma} d \vec{l}+\oint(\vec{u} \times \vec{B}) d \vec{l} .
$$

The integration in (1) is taken along the contour: the voltmeter - the lead - the shunt part - the lead. the voltmeter. In (1) $\Phi$ is the magnetic flux through the contour, $j$ is the current density, $\vec{u}$ is the mass velocity in the contour reference system, $\vec{B}$ is the magnetic field. As the current flowing through the cell is invariable, then $\Phi=$ const and the first term in (1) is vanishing. The third summand can also be omitted As a matter of fact, if the measuring contour is stationary relative to the cell $(u=0)$, then the summant equals zero. The condition $u=0$ for all contour parts is not, of course, fulfilled (the leads are connected to the cable outside the shock region). At the same time, the magnetic field is small far away from the shunt the angle between the vectors $\vec{u}$ and $\vec{B}$ is also small, hence the third term in (1) is truly negligible. Thus. the only second summand remains in (1). Taking into account that the measuring unit (the voltmeter) does not use any current, the contour integral is reduced to the linear integral along the shunt part. For the 10 case the voltage registered as $V(t)$ is very simply related to the electric field at the shunt-specimen interface $E_{s s}(t)$ :

$$
\frac{V(t)}{V_{0}}=\frac{E_{s s}(t)}{E_{0}},
$$

where $V_{0}$ is the voltage, $E_{0}$ is the electric field in the cell at the initial instant of time (before entering: shock wave into the matter).

Further it needs to be ascertained how the electric field at the shunt-specimen interface is connected with the matter conductivity behind the shock front. 


\section{THE PROCESS MODEL AND ITS ANALYSIS}

We use the following model of the process: 1) the shock wave propagates permanently with the same parameters, 2) the mass and shock velocities are negligible compared to the light velocity, 3) the electroconductivity of the shunt and the compressed matter are time-independent, 4) the matter conductivity arises instantaneously behind the shock front, 5) at the initial instant of time the current distribution through the shunt is uniform. Let $D$ is the shock velocity, $U$ is the mass velocity, $x_{1}$ is the shunt thickness, $\sigma_{1}$ is the shunt conductivity, $\sigma_{2}$ is the matter conductivity at the compressed state. In the reference system fixed to the shunt-specimen interface the 1D problem of the magnetic diffusion in two conductive regions is described by the following system of equations

$$
\begin{array}{cc}
\frac{\partial B_{1}}{\partial t}-\frac{1}{\mu_{0} \sigma_{1}} \frac{\partial^{2} B_{1}}{\partial x^{2}}=0, & \frac{\partial B_{2}}{\partial t}-\frac{1}{\mu_{0} \sigma_{2}} \frac{\partial^{2} B_{2}}{\partial x^{2}}=0, \\
B_{1}\left(-x_{1}, t\right)=B_{0}, & B_{2}((D-U) t, t)=-B_{0}, \\
B_{1}(0, t)=B_{2}(0, t), & \left.\frac{1}{\sigma_{1}} \frac{\partial B_{1}}{\partial x}\right|_{x=0}=\left.\frac{1}{\sigma_{2}} \frac{\partial B_{2}}{\partial x}\right|_{x=0}, \\
B_{1}(x, 0)=-B_{0}\left(1+2 \frac{x}{x_{1}}\right) . &
\end{array}
$$

The equations (2) represent the magnetic diffusion equations for two regions. The region 1 is the shunt $\left(-x_{1} \leq x \leq 0\right)$, the region 2 is the conductive matter $(0 \leq x \leq(D-U) t)$. The magnetic field $B$ at the region boundaries are defined by (3). The total current through the cell is constant, therefore the boundary field $B_{0}$ is also constant. The equations (4) express the continuity conditions of the magnetic and electric fields at the shunt-specimen interface. The equation (5) defines the uniform distribution of the current in the shunt at the initial instant of time.

The difficulty of solving the boundary value problem (2)-(5) is caused by the fact that the boundary of the matter region is moving, which give no way of using the well-known methods for solving the diffusion equation. To solve the problem we expand the domain of the values $x, t$ from the triangle form (that is defined by the lines $x=0$ and $x=(D-U) t)$ to the quarter plane $(x>0, t>0)$. Then we construct the Green function for the new region and use the Laplace transformation method [6]. The solution of the boundary problem (2)-(5) has the following form:

for the shunt region

$$
\begin{gathered}
\frac{B_{1}(x, t)}{B_{0}}=-1-2 \xi+\frac{4}{\sqrt{\pi}} \int_{0}^{\infty} \frac{g(\eta)}{\operatorname{cth}(\sqrt{R} \eta)+\sqrt{s}} G(\xi, \tau, \eta) d \eta, \\
G(\xi, \tau, \eta)=\sum_{n=0}^{\infty} \exp \left\{-\frac{1}{4 \tau}[-\xi+2 n+2 \sqrt{\tau} \eta]^{2}\right\}-\exp \left\{-\frac{1}{4 \tau}[\xi+2(n+1)+2 \sqrt{\tau} \eta]^{2}\right\},
\end{gathered}
$$

for the conductive matter region

$$
\frac{B_{2}(x, t)}{B_{0}}=-1+\frac{4}{\sqrt{\pi}} \exp \left(-\frac{\varphi^{2} R}{4}\right) \int_{0}^{\infty} f(\eta) \operatorname{sh}[(1-\varphi) \sqrt{R} \eta] \exp \left(-\eta^{2}\right) d \eta
$$




$$
\begin{gathered}
f(\eta)=\frac{g(\eta)}{\operatorname{ch}(\sqrt{R} \eta)+\sqrt{s} \operatorname{sh}(\sqrt{R} \eta)}, \\
g(\eta)=2 \sqrt{\tau s} \eta, \quad 0 \leq \eta \leq \frac{1}{\sqrt{\tau}}, \\
g\left(\eta+\frac{1}{\sqrt{\tau}}\right)=\frac{1-\sqrt{s} \operatorname{th}(\sqrt{R} \eta)}{1+\sqrt{s} \operatorname{th}(\sqrt{R} \eta)} g(\eta)+2 \sqrt{s}
\end{gathered}
$$

The dimensionless variables are used in (6)-(11)

$$
\varphi=\frac{x}{(D-U) t}, \quad R=\mu_{0} \sigma_{2}(D-U)^{2} t, \quad s=\frac{\sigma_{2}}{\sigma_{1}}, \quad \tau=\frac{t}{\mu_{0} \sigma_{1} x_{0}^{2}}, \quad \xi=\frac{x}{x_{1}},
$$

where $\varphi$ is the coordinate in the compressed matter, $R$ is the parameter defining the electromagnetic processes in the matter, $s$ is the ratio of the specimen conductivity to the shunt one, $\tau$ is the observation time divided by the diffusion time in the shunt, $\xi$ is the coordinate in the shunt region.

The solution (6)-(11) allows one to obtain the electric field in the $i$ region

$$
E_{i}=-\frac{1}{\mu_{0} \sigma_{i}} \frac{\partial B_{i}}{\partial x} \text {. }
$$

The dependencies of the electric field at the shunt-specimen interface $E_{s s}$ on the dimensionless time $\theta=t D / x_{1}$ are shown on Fig. 2 by solid lines. The magnetic Reynolds number of the shunt $R e_{m}=\mu_{0} \sigma_{1} D x_{1}$ is used here as a parameter. For the dependencies on the Fig. $2 R e_{m}=1, U / D=0.5$ and the parameter $s$ varies within $0.02 \div 50$. For comparison, the dependence corresponding to the electromagnetic equilibrium in the system is shown on the figure by the dash line for $s=1$.

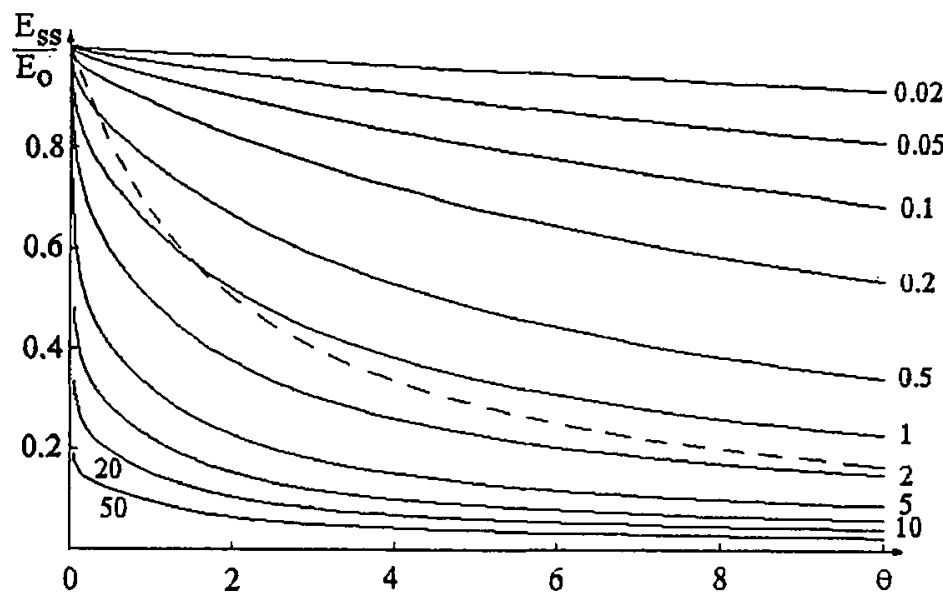

Figure 2: The results of modelling: the time dependence of the electric field at the shunt-specimen interface (the parameter $s$ is marked at the corresponding curves). The dash line corresponds the electromagnetic equilibrium conditions for $s=1$.

As can be seen from Fig. 2, in the electromagnetic nonequilibrium conditions the time dependence of the electric field is highly affected by the ratio of the matter conductivity to the shunt conductivity $s$. This fact is of great importance for the justification of the conductivity measurement by the present method. To obtain the conductivity one can compare the experimental dependence $V(t)$ and the model dependence set 


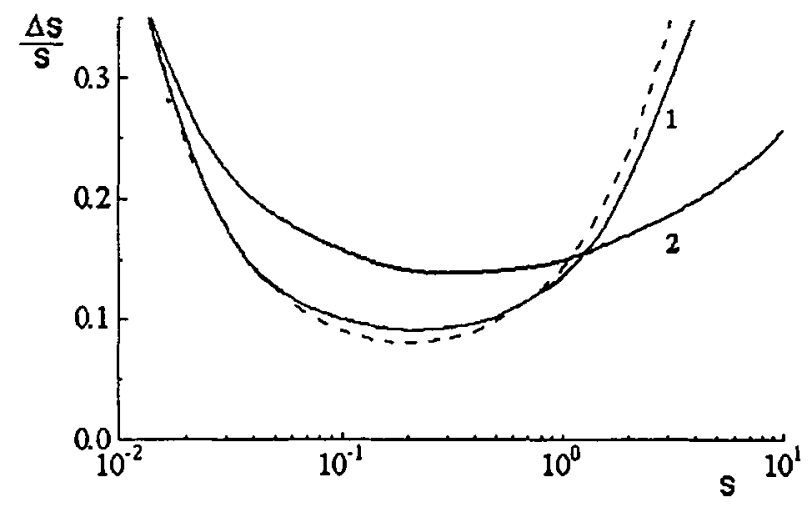

Figure 3: The dependencies of the conductivity error on the parameter $s$. The model parameters: $U / D=0.5, \theta=10$, $R e_{m}=1$ (the curve 1 ), $R e_{m}=10$ (the curve 2). The dash line marks the equilibrium conditions.

$E_{s s}(s, \theta)$. The model curve giving the best fit to the experimental dependence provides the unknown conductivity value.

The accuracy of determining the conductivity can be estimated by the method. Let the voltage error $\Delta V / V_{0}$ be $2 \%$. Find the corresponding values of the conductivity error. The results of the analysis are shown on Fig. 3. When taking measurements in the electromagnetic nonequilibrium conditions, the conductivity error is higher than one for equilibrium conditions. At the same time, deterioration of accuracy has no catastrophic nature. The matter conductivity can be measured within $\approx 10 \div 15 \%$ under the dielectric-metal transition in a shock wave.

\section{THE INTERPRETATION OF THE EXPERIMENTAL RECORD}

An experimental record is shown on Fig. 4 by the solid line. It is obtained in the test with the highly porous aluminium PAP-1. Initially, the powder is nonconducting, its density is about $0.5 \mathrm{~g} / \mathrm{cm}^{3}$. The shock pressure in the powder is $1.7 \mathrm{GPa}$. The constantan foil $100 \mu \mathrm{m}$ thick and $10 \mathrm{~mm}$ width is used as a shunt.

The results of modelling the electromagnetic response of the cell for the model developed in the previous section are shown on Fig. 4 by the dotted lines. Three dependencies differ by the conductivity value of $\sigma_{2}$. The middle curve corresponds to the conductivity $\sigma_{2}^{*}=2.3 \cdot 10^{6} \mathrm{Om}^{-1} \mathrm{~m}^{-1}$. For outer curves the conductivity varies by $\pm 20 \%$ relative to the middle curve. The model parameters are $R e_{m}=0.61$, $U / D=0.8, s=1.2$ (for the middle curve). The figure gives indication of the agreement of the experimental data and the model. It gives also insight into the accuracy of determining the matter conductivity by the method.

The possibility of using the model (2)-(5) to describe the experimental results is due to a number of requirements stated in the section 3. Most of them can be checked a priori. At the same time, the assumption of the nature of occurrence and change for the matter conductivity cannot be proved before the experiment. The constant conductivity requirement is essentially used in the model (2)-(5), which has allowed us to find the rigorous solution (6)-(11). The possible approach to settle the problem uncertainty is to analyse the effect of the factors of interest to us on the time dependencies of the voltage and to compare them with the experimental data. To study the effect of the time-dependent conductivity the numerical analysis is performed for the shunt-specimen system for increasing and decreasing the matter conductivity. The corresponding dependencies are marked on Fig. 4 by the dash lines. The curve 1 denotes the linear rise of the conductivity from 0 to $2 \sigma_{2}^{*}$, the curve 2 fits the linear decrease from $2 \sigma_{2}^{*}$ to 0 . As can be seen from Fig. 4, the experimental time dependence $V(t)$ can be treated quite reliable as a result of generation of the 


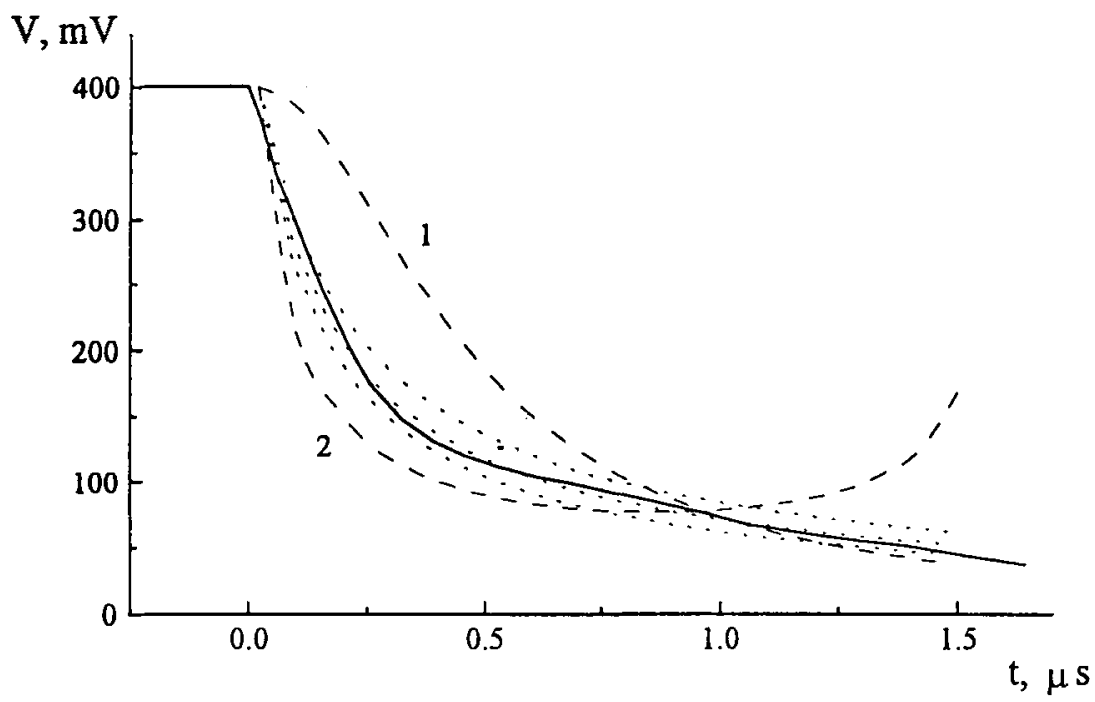

Figure 4: The experimental dependence of the voltage on the time (solid line) and the model dependencies: the dotted lines. mark the matter conductivity is time-independent (the conductivity for outer lines differs from central one by $\pm 20 \%$ ), the dash lines mark the matter conductivity is time-dependent ( 1 - the conductivity increases, 2 - the conductivity decreases).

constant conductivity region in the aluminium powder in step of propagating the shock wave through the matter. Thus, the step-like model of the conductivity change behind the shock front can be used for treating the experimental voltage records.

\section{THE CONCLUSION}

The analysis made is the basis for developing the new technology of the conductivity measurement of condensed matter in dynamic experiment. The examination of the transient electromagnetic processes enables one for the first time to study the dielectric-metal transition in a shock wave.

\section{Acknowledgement}

The authors are grateful to A.M.Trubachev for useful discussions.

\section{References}

[1] Alder B.J., Solids under Pressure (McGraw-Hill, New York, 1963) pp. 385.

[2] Styris D.L., Duvall G.E., High Temp. - High Press., 2, (1970) 477-499.

[3] Keeler R.N., Physics of High Energy Density (Academic Press, New York, London, 1971) pp. 106125.

[4] Yakushev V.V., Combust. Explos. Shock Waves, 14, (1978) 131-146.

[5] Gilev S.D., "Electromagnetic methods for investigation of chemical and phase transformations of solids in a shock wave", Metaliurgical and Material Applications of Shock-Wave and High-Strain-Rate Phenomena, El Paso 6-10 August 1995, L.E. Murr, K.P. Staudhammer, M.A. Meyers Eds. (Elsevier, Amsterdam, 1995) pp. 785-792.

[6] Gilev S.D., Michailova T.Yu., Tech. Phys., 41, No. 10 (1996). 